\title{
ECOPHENOTYPIC VARIATION AND PHYLOGENY WITHIN THE ERISOCRINACEA (CRINOIDEA): LINKAGE OF MORPHOLOGY, ECOLOGY, \& SEA - LEVEL IN THE LATE PALEOZOIC
}

HOLTERHOFF, Peter F., Dept. of Geology, Univ. of Cincinnati, Cincinnati, $\mathrm{OH} 45221-0013$

Cyclothems (fifth - order depositional sequences) are the fundamental stratigraphic motif of the Upper Pennsylvanian and Lower Permian of the North American mid - continent. Through this interval, sequences display an overall second order regression modulated by intermediate frequency sea level fluctuations. Thus, shelfward incursions of offshore (basinal) facies are more extensive in the lower Upper Pennsylvanian, while merely shoaling facies characterize marine units of many higher sequences.

Within basal Upper Pennsylvanian (Missourian) sequences, species of the Erisocrinacea are ubiquitous members of nearshore and offshore crinoid assemblages. However, the species Erisocrinus typus and Delocrinus subhemisphericus display significant ecophenotypic variation between facies: smaller mean and maximum size characterizes offshore/transgressive populations while larger size characterizes nearshore/regressive populations. It is proposed that these are hydrographically - controlled phenotypes: offshore, quiet bottom waters inhibit effective filtration, imposing a metabolic energy threshold beyond which larger morphologies are not viable while nearshore populations are able to assume larger body sizes.

Shifting now to the Catacrinidae within the Erisocrinacea, as the frequency of interbasinal drowned shelf conditions waned through the Late Pennsylvanian, new species, inhabiting regressive facies, increased maximum body size and diversity for the family. Thus, lower Virgilian assemblages are highly variable in characteristic size, with smaller, ancestral $D$. subhemisphericus dominant in offshore facies while robust $D$. vulgatus, Pyndaxocrinus sp., and Arrectocrinus sp. dominate nearshore facies. Speciation may have involved the stabilization and subsequent diversification of the earlier nearshore phenotype.

Through the remainder of the Virgilian and into the Early Permian, near the terminal late Early Permian regression, larger morphologies, represented by $D$. brownsvillensis, $D$. vastus, and $A$. abruptus, dominate midcontinent crinoid assemblages; smaller offshore species had been lost, thus increasing body size for the clade as a whole.

Thus, it appears that the same parameters which controlled morphological expression at the fifth - order level (ecophenotypic variation) may also have acted at the second - order level (phylogenetic trend). The interrelationship between sub-cycle and super-cycle sea - level and metabolic viability is paramount to understanding potential morphologies for this clade. However, these factors may not have ultimately influenced clade diversity. 